\title{
PRESSUPOSTOS PARA A ELABORAÇÃO DE RELATO DE EXPERIÊNCIA COMO CONHECIMENTO CIENTÍFICO
}

\author{
ASSUMPTIONS FOR THE PREPARATION OF AN EXPERIENCE REPORT AS \\ SCIENTIFIC KNOWLEDGE
}

\section{SUPUESTOS PARA LA PREPARACIÓN DE UN INFORME DE EXPERIENCIA COMO CONOCIMIENTO CIENTÍFICO}

\author{
Ricardo Franklin de Freitas Mussi \\ Universidade do Estado da Bahia - Brasil \\ Fábio Fernandes Flores \\ Universidade do Estado da Bahia - Brasil \\ Claudio Bispo de Almeida \\ Universidade do Estado da Bahia - Brasil
}

\begin{abstract}
Resumo: Aceitando a experiência como o ponto de partida para a aprendizagem, manuscrito do tipo relato de experiência permitem a apresentação crítica de práticas e/ou intervenções científicas e/ou profissionais. Neste sentido, é fundamental que sua escrita garanta sua apresentação a partir da perspectiva acadêmica. Assim, o presente texto objetiva discutir os pressupostos teóricos e estruturantes para elaboração de relatos de experiências colaborativos para a construção de conhecimento. Metodologicamente trata-se de estudo no formato de ensaio acadêmico-científico. A principal contribuição versa da apresentação de roteiro para a descrição e critica reflexiva da experiência relatada. Assim, é sugerido que o seguimento do relato propriamente seja composto por quatro tipos de descrição: informativa, referenciada, dialogada e crítica, conforme seus elementos e respectiva pergunta facilitadora para apresentação da informação. Entende-se que a proposta contribuirá na compreensão do relato de experiência enquanto modalidade de escrita acadêmica importante para a produção do conhecimento, especialmente para a melhoria das ações científicas e profissionais.
\end{abstract}

Palavras chave: Conhecimento científico; Relato de experiência; Produção do conhecimento.

\begin{abstract}
Accepting experience as the starting point for learning, experience report-type manuscripts allow for the critical presentation of scientific and/or professional practices and/or interventions. In this sense, it is essential that your writing guarantees its presentation from an academic perspective. Thus, this text aim to discuss the theoretical and structuring assumptions for the elaboration of collaborative experience reports for the construction of knowledge. Methodologically, it is a study in the form of an academic-scientific essay. The main contribution comes from the presentation of a script for the description and reflexive critique of the reported experience. Thus, it is suggested that the follow-up of the report itself is composed of four types of description: informative, referenced, dialogued and critical, according to its elements and respective facilitating question for the presentation of information. It is understood that the proposal will contribute to the understanding of experience reporting as an important academic writing modality for the production of knowledge, especially for the improvement of scientific and professional actions.
\end{abstract}

Keywords: Scientific knowledge; Experience report; Knowledge production. 
Resumen: Aceptando la experiencia como punto de partida para el aprendizaje, los manuscritos tipo informe de experiencia permiten la presentación crítica de prácticas y/o intervenciones científicas y/o profesionales. En este sentido, es fundamental que tu escritura garantice su presentación desde una perspectiva académica. Así, este texto tiene como objetivo discutir los supuestos teóricos y estructurantes para la elaboración de informes de experiencias colaborativas para la construcción del conocimiento. Metodológicamente, es un estudio en forma de ensayo académico-científico. El aporte principal proviene de la presentación de un guión para la descripción y crítica reflexiva de la experiencia relatada. Así, se sugiere que el seguimiento del propio informe se componga de cuatro tipos de descripción: informativa, referenciada, dialogada y crítica, según sus elementos y respectiva pregunta facilitadora para la presentación de información. Se entiende que la propuesta contribuirá a la comprensión del relato de experiencias como una modalidad de redacción académica importante para la producción de conocimiento, especialmente para la mejora de las acciones científicas y profesionales.

Palabras clave: Conocimiento científico; Informe de experiencia; Producción de conocimiento.

\section{Introdução}

A humanidade apresentou, ao longo da história, intensas mudanças nas características relativas à produção, divulgação e apropriação do conhecimento. Destarte, parece crescente a possibilidade da conformação de uma sociedade do conhecimento, o que demanda a continuidade do aperfeiçoamento/qualificação das estratégias para ampliação do acesso e compreensão das descobertas/produções científicas e tecnológicas pelos mais diferentes públicos.

De maneira complementar, é importante que esta divulgação fomente panoramas compreensivos, a partir de parâmetros críticos e reflexivos. Assim, esta divulgação assume o compromisso relativo a difusão das informações oriundas da construção/produção científica valendo-se de instrumentos, metodologias e mecanismos que proporcionem (re)codificações do conhecimento para linguagens mais acessíveis às diferentes comunidades (BUENO, 2010).

Dentre as variadas possibilidades de divulgação científica o texto escrito figura como um dos principais métodos. A publicação de textos científicos é uma maneira recorrente das(os) especialistas fazerem com que seus achados e reflexões sejam acessados e discutidos pelos seus pares do campo acadêmico e pela sociedade de maneira geral, positiva ao bem comum. Os manuscritos mais lidos são aqueles que apresentam informações de interesse e com escrita que potencialize sua leitura, especialmente diante da crescente quantidade de publicações (PEREIRA, 2018).

Então, é importante as autorias compreenderem a melhor maneira para estruturação do texto acadêmico, incluindo as questões léxico-gramaticais, semântico-discursivas e as relações de contextos em que a redação ocorre (VIAN JUNIOR; MENDES, 2015). Mais que simplesmente comunicar a produção, a publicação comprometesse com o chamamento social 
para atuação na construção da ciência, contribuindo na decisão de seus rumos (ANGELO et al, 2020).

A partir da constatação da importância da elaboração e divulgação do conhecimento científico, emerge a necessária compreensão das diferentes possibilidades metodológicas e, também, das variadas modalidades para proposição e estruturação dos escritos acadêmicos, tais como, o relato de experiência (RE). Destaca-se que o RE não é, necessariamente, um relato de pesquisa acadêmica, contudo, trata do registro de experiências vivenciadas (LUDKE; CRUZ, 2010). Tais experiências podem ser, por exemplo, oriundas de pesquisas, ensino, projetos de extensão universitária, dentre outras.

Diante de buscas, quer seja por meio de livros, ou por material digital (textos em revistas científicas e/ou bibliotecas virtuais), notou-se a restrita disponibilidade de referências dedicadas à discussão e compreensão acerca do RE enquanto modalidade de redação crítica-reflexiva.

De maneira geral, quando encontradas, as referências reportam sugestões quanto a estruturação dos relatos, tais como as indicações da revista chilena Psicoperspectivas Individuo y sociedad ${ }^{1}$ e o instrutivo da Universidade Federal de Juiz de Fora (UFJF) ${ }^{2}$, e ainda orientações para a construção formal (DALTRO; FARIA, 2019).

A primeira referência apresenta designações de acordo as seções do artigo, e a segunda perguntas balizadoras para a escrita. Ambas carecendo de argumentação teórico-metodológica quanto a proposição dos seus elementos constitutivos.

A terceira referência apresenta seis elementos essenciais na elaboração do texto. Embora seja destacado o potencial desta escrita, contenha críticas e aspectos que fazem parte do RE, não é apresentado de forma específica os vários elementos e as explicações para a sua presença no artigo. Perante este cenário, torna-se preponderante a realização de estudos, críticas e reflexões que abordem o RE enquanto modalidade de redação acadêmico-científica. Especialmente para a superação da mera questão normativa/estruturante, contribuindo para o aperfeiçoamento da compreensão e qualificação da construção/discussão do conhecimento a partir de ações crítica-reflexivas da experiência.

Tendo em vista a preocupação com os saberes no campo científico, Ciarallo (2019) cita três critérios de cientificidade para a produção acadêmica que devem ser compartilhados por diferentes áreas da pesquisa/escrita em ciências, a saber: a coerência, a consistência e a objetivação. Neste sentido, o presente manuscrito abordará informações acerca do

\footnotetext{
${ }^{1}$ Disponível em: http://pepsic.bvsalud.org/pdf/psicope/pdf1.pdf

${ }^{2}$ Disponível em: https://www.ufjf.br/nutricaogv/files/2016/03/Orienta\%C3\%A7\%C3\%B5es-

Elabora\%C3\%A7\%C3\%A3o-de-Relato-de-Experi\%C3\%AAncia.pdf
} 
conhecimento relativo à redação científica, especificamente quanto a sua produção e divulgação por meio dos RE, ratificando a sua importância em diferentes cenários nas Instituições de Ensino Superior, materializado por meio das publicações.

Em seguida, expõe-se a sugestão de um roteiro para construção de RE, resultante de um processo contínuo de amadurecimento, sendo composto por: elaboração, participação, orientação e apresentação de estudos no formato de RE. E tem como propósito auxiliar na edificação e organização de RE crítico-reflexivo ao elencar elementos importantes que precisam ser contemplados, uma vez que escritas desta natureza contribuem importantemente na produção de conhecimento científico.

É importante destacar que a produção científica é um dos aspectos que compõe a formação acadêmica profissional, pois há uma relação direta com a construção de novos saberes, tendo a leitura e a escrita como condições para o ideal desenvolvimento investigativo (STOCKMANNS et al., 2018) e a assertiva apresentação de seus achados. Diante deste contexto, é fundamental o entendimento das escritas científicas (OLIVEIRA JUNIOR, 2015) e cuidados na edificação do manuscrito acadêmico, considerando a qualidade redacional do texto, a estrutura organizada/coerente, o propósito inicial e a objetividade (PEREIRA, 2012a).

Neste contexto, em estudo realizado com trabalho publicados por professores em forma de RE (LUDKE; CRUZ, 2010), observou-se que além da qualidade da escrita, existia uma preocupação com o conteúdo abordado, o qual deve não ser superficial, não deixar relatos da prática subentendidos, e nem constar excessivamente uma discussão bibliográfica, e deve constar os aspectos positivos e negativos da experiência vivenciada.

Face ao exposto, este ensaio teórico (SOARES; PICOLLI; CASAGRANDE, 2018) objetiva discutir os pressupostos teóricos e estruturantes para elaboração de relatos de experiências colaborativos para a construção de conhecimento.

\section{Conhecimento, Experiência e Relato de Experiência}

Ao considerar o RE como expressão escrita de vivências, capaz de contribuir na produção de conhecimentos das mais variadas temáticas, é reconhecida a importância de discussão sobre o conhecimento. O conhecimento humano está interligado ao saber escolarizado e aprendizagens advindas das experiências socioculturais. $\mathrm{O}$ seu registro por meio da escrita é uma relevante possibilidade para que a sociedade acesse e compreenda questões acerca de vários assuntos, sobretudo pelo meio virtual, uma vez que o contexto contemporâneo informatizado possibilita isso. Deste modo, o conhecimento tem como objetivo a formação dos sujeitos na própria sociedade (CÓRDULA; NASCIMENTO, 2018). 
São amplamente reconhecidas e debatidas quatro principais maneiras para a composição do conhecimento, a saber: popular, religioso, filosófico e científico (CHAUÍ, 2014). O conhecimento popular origina-se da transmissão por meio de interações educacionais informais, sobretudo entre integrantes de diferentes gerações que compõem a comunidade, assim, baseiase apenas nas experiências pessoais das pessoas. O conhecimento religioso, por ser teológico, funda-se exclusivamente nas doutrinas e proposições sagradas, embora seja sistemático, suas evidências não são verificadas e/ou verificáveis. A compreensão filosófica da realidade, apesar de não permitir verificação, fundamenta-se no exercício racional e sistemático do pensamento. A apreensão do conhecimento por meio do modelo científico, diferencia-se das demais por emergir do contexto metodológico, permeado pela sistematização e reflexão.

Neste contexto, a atitude científica distingue-se do senso comum e da religiosidade pelo fomento e valorização da desconfiança das certezas e, da filosofia ao assumir o rigor técnicometodológico como diretriz fundante de sua rotina constitutiva.

A experiência "é vivida antes de ser captada pelo pensamento, apreendida pela reflexão, caracterizada em seus componentes" (BRETON; ALVES, 2021, p.3), portanto, é ela "que desperta o poder de conhecer" (MENEZES, 2021, p.10). Em seu domínio ocorrem as aprendizagens (KASTRUP, 2008). Apesar de não ser a única ou exclusiva maneira para seu atingimento, não se "pode aprender pela experiência do outro, a não ser que essa experiência seja revivida e tornada própria" (CAPOZZOLO et al, 2013).

Além disso, é fundamental a identificação, diferenciação e associação crítica-reflexiva entre a experiência próxima e distante (GEERTZ, 2004). Com a primeira relativa à vivência propriamente dita, presente de maneira informal, sem a necessidade de ação critica-reflexiva e sua (re)aplicação em outras situações ou com outras pessoas. Enquanto a segunda, é empregada de maneira intencional para compreensão, crítica e reflexão diante dos acontecimentos, ou seja, constituição analítica do conhecimento.

Então, o RE em contexto acadêmico pretende, além da descrição da experiência vivida (experiência próxima), a sua valorização por meio do esforço acadêmico-científico explicativo, por meio da aplicação critica-reflexiva com apoio teórico-metodológico (experiência distante).

Dentre as áreas que usam o RE, duas são comumente encontradas, a Educação (integrante da grande área Humanas), tendo como subáreas: Ensino e Aprendizagem, Teorias da Instrução, Métodos e Técnicas de Ensino, Avaliação da Aprendizagem e Currículo, e também, a de Ensino (integrante da grande Área Multidisciplinar), tendo como subáreas: propostas educativas e Ensino de determinado conteúdo (DIAS; THERRIEN; FARIAS, 2017). 
Nas Instituições de Ensino Superior (IES), o RE faz parte dos estudos publicados por docentes e discentes nos três pilares: ensino, pesquisa e extensão. No ensino, as ações durante os componentes curriculares, sobretudo os estágios, representam momentos edificantes para a formação acadêmica, profissional e humana (FLORES et al., 2019), além disso podem ajudar na compreensão das especificidades, como por exemplo a utilização de materiais didáticos voltados a determinada população (PAIVA; MATOS, 2019). Na pesquisa, as vivências possibilitam aprendizagens e reflexões sociohistóricas, bem como enriquecimento cultural (MUSSI et al., 2020). Na extensão, a atuação em projeto é relevante, uma vez que tal experiência pode ter impactos positivos na atuação enquanto futuros profissionais de educação (ALMEIDA, 2016).

Ainda nas IES, no campo da graduação, o RE pode ser advindo da educação formal por meio de participações de diferentes programas: Programa Institucional de Bolsas de Iniciação à Docência - PIBID (ABREU; NÓBREGA-THERRIEN, 2021) e a Residência pedagógica (SOUSA; BARROSO, 2019); da educação não formal, a exemplo de uma escola de educação especial (HENDGES, 2019); e de intercâmbio, por intermédio do programa Bramex (MACHADO, 2020). Podendo ainda ser no campo da pós-graduação, como na Residência Multiprofissional (OSSEGE et al., 2020).

\section{Roteiro para Relato de Experiência}

O Relato de experiência é um tipo de produção de conhecimento, cujo texto trata de uma vivência acadêmica e/ou profissional em um dos pilares da formação universitária (ensino, pesquisa e extensão), cuja característica principal é a descrição da intervenção. Na construção do estudo é relevante conter embasamento científico e reflexão crítica.

A produção de estudos tem como finalidade contribuir para o progresso do conhecimento, sendo assim tornam-se relevantes trabalhos que abordem a sistematização da construção de estudos da modalidade RE, uma vez que o saber científico contribui na formação do sujeito e a sua propagação está relacionada com a transformação social (CÓRDULA; NASCIMENTO, 2018).

Na sequência, será apresentada uma sugestão de roteiro para construção do RE como possibilidade de uso, sobretudo, na área de educação e ensino. O Quadro 1 cita as seções do artigo e elenca os elementos de cada seção com sua respectiva pergunta facilitadora para a descrição, de modo que o autor ou autora possa compreender e contemplar informações peculiares no artigo. 
Quadro 1 - Sugestão de roteiro para construção do RE

\begin{tabular}{|c|c|c|c|}
\hline $\begin{array}{l}\text { SEÇÃO DO } \\
\text { ARTIGO }\end{array}$ & $\begin{array}{l}\text { ELEMENTOS DA } \\
\text { SEÇÃO }\end{array}$ & $\begin{array}{l}\text { PERGUNTA FACILITADORA PARA } \\
\text { DESCRIÇÃO. }\end{array}$ & $\begin{array}{c}\text { TIPOS DE } \\
\text { CATEGORIAS } \\
\text { (DESCRIÇÃO) }\end{array}$ \\
\hline \multirow[t]{2}{*}{ Introdução } & 1. Campo teórico & $\begin{array}{l}\text { - Quais são os conceitos chaves do tema? } \\
\text { - Qual a importância deste relato? } \\
\text { - Por que escrever este relato? } \\
\text {-Adveio de qual problema? }\end{array}$ & Referenciada \\
\hline & 2. Objetivo & Qual o objetivo deste relato? & Informativa \\
\hline \multirow{11}{*}{$\begin{array}{l}\text { Materiais e } \\
\text { Métodos / } \\
\text { Procedimentos } \\
\text { metodológicos }\end{array}$} & 3. Período temporal & $\begin{array}{l}\text { Quando (data)? Quanto tempo (horas, } \\
\text { dias ou meses)? }\end{array}$ & Informativa \\
\hline & 4. Descrição do local & $\begin{array}{l}\text { Quais são as características do local e } \\
\text { onde fica situado geograficamente } \\
\text { (cidade, estado e país)? }\end{array}$ & Informativa \\
\hline & 5. Eixo da experiência & Do que se trata a experiência? & Informativa \\
\hline & $\begin{array}{l}\text { 6. Caracterização da } \\
\text { atividade relatada }\end{array}$ & Como a atividade foi desenvolvida? & Informativa \\
\hline & 7. Tipo da vivência & Qual foi o tipo de intervenção realizada? & Informativa \\
\hline & $\begin{array}{l}\text { 8. Público da ação } \\
\text { interventiva }\end{array}$ & $\begin{array}{l}\text { Qual o perfil ou característica destas } \\
\text { pessoas? }\end{array}$ & Informativa \\
\hline & 9. $\quad$ Recursos & $\begin{array}{l}\text { O que foi usado como material na } \\
\text { intervenção? }\end{array}$ & Informativa \\
\hline & 10. Ação & O que foi feito? E como foi feito? & Referenciada \\
\hline & 11. Instrumentos & $\begin{array}{l}\text { Quais foram as formas e materiais } \\
\text { utilizados para coletar as informações? }\end{array}$ & Referenciada \\
\hline & 12. Critérios de análise & $\begin{array}{l}\text { Como ocorrerá a análise das informações } \\
\text { obtidas? }\end{array}$ & Referenciada \\
\hline & 13. Eticidade & De quais formas houve o cuidado ético? & Informativa \\
\hline Resultados & 14. Resultados & $\begin{array}{l}\text { Quais foram os resultados advindo da } \\
\text { experiência? Quais foram as principais } \\
\text { experiências vivenciadas? }\end{array}$ & Informativa \\
\hline \multirow[t]{5}{*}{ Discussão } & $\begin{array}{l}\text { 15. Diálogo entre o relato } \\
\text { e a literatura }\end{array}$ & $\begin{array}{l}\text { Quem (na literatura) pode dialogar com } \\
\text { minhas informações do relato? }\end{array}$ & Dialogada \\
\hline & $\begin{array}{l}\text { 16. Comentário acerca das } \\
\text { informações do relato }\end{array}$ & $\begin{array}{l}\text { Quais nexos complementares podem ser } \\
\text { feito com os dados da experiência? }\end{array}$ & Dialogada \\
\hline & $\begin{array}{l}\text { 17. Análise das } \\
\text { informações do RE }\end{array}$ & $\begin{array}{l}\text { Quais reflexões críticas o texto faz? } \\
\text { Como os resultados desta experiência } \\
\text { podem ser explicados por outros } \\
\text { estudos? (artigos, outros RE, dentre } \\
\text { outros) }\end{array}$ & Crítica \\
\hline & 18. Dificuldades & $\begin{array}{l}\text { Quais foram os aspectos que } \\
\text { dificultaram o processo? } \\
\text { (Limitações) O que foi feito perante } \\
\text { essas limitações? }\end{array}$ & Informativa \\
\hline & 19. Potencialidades & $\begin{array}{l}\text { Quais foram os aspectos que } \\
\text { potencializaram o processo? }\end{array}$ & Informativa \\
\hline \multirow{2}{*}{$\begin{array}{l}\text { Considerações } \\
\text { finais ou } \\
\text { conclusão }\end{array}$} & 20. Finalidade & O intuito do relato foi alcançado? & Informativa \\
\hline & 21. Proposições & $\begin{array}{l}\text { Além do que fora realizado, o que mais } \\
\text { poderia ser feito? }\end{array}$ & Informativa \\
\hline Referência & 22. Citação & $\begin{array}{l}\text { Quais estudos foram usados para a } \\
\text { construção do RE? }\end{array}$ & Informativa \\
\hline
\end{tabular}




\section{Justificativa e discussão sobre a proposta}

A organização do trabalho científico difere conforme o seu tipo (relatório de pesquisa, monografia, dissertação, tese e artigo), tendo como base o manuscrito, o corpo do seu texto é dividido em cinco seções: introdução, material e métodos, resultados, discussão e conclusões, podendo sofrer alterações (MARCONI; LAKATOS, 2013), e com o RE não é diferente.

De maneira aditiva, a redação do artigo é igualmente importante. Deste modo, é necessário um preparo para que as seções tenham uma sequência lógica de argumentos para possibilitar uma leitura fluída e contínua (PEREIRA, 2012a). Em alguns pontos, nota-se a similaridade entre a escrita de um RE com a de um artigo científico, pois ambos necessitam de uma estrutura que contenham perguntas norteadoras e embasamento teórico, como por exemplo: introdução, métodos, resultados e discussão.

Tendo como parâmetro a estrutura supramencionada, a introdução contempla o campo teórico, também nomeado de referencial teórico, que "deve conter um apanhado do que existe, de mais atual na abordagem do tema escolhido, mesmo que as teorias atuais não façam parte de suas escolhas" (MARION; DIAS; TRALDI, 2002, p.38). Sendo assim, compreende a menção do que tem nas escritas acadêmicas científicas (livros, artigos, monografias, dissertações e teses) sobre o assunto a ser tratado no RE, sendo importante contemplar os aspectos necessários para que o(a) leitor(a) entenda a conjuntura de forma coerente. Em suma, é composto pela relevância, bases conceituais e teóricas fundamentais, a justificativa e ao final o objetivo (PEREIRA, 2012b).

Nos materiais e métodos serão descritas as características e etapas desde o planejamento até o desenvolvimento da atividade, incluindo a dinâmica analítica que será adotada. Relacionando com o RE, dos tópicos presentes na estrutura do Método de Pereira (2013a) podese utilizar o cenário (contexto), amostra (quem participou da vivência), coleta de dados (procedimentos e instrumentos), intervenção (ação realizada) e aspectos éticos necessários. Esta seção é composta por 11 elementos: Período temporal (data e duração), Descrição do local, Eixo da experiência, Caracterização da atividade relatada, Tipo da vivência, Público da ação interventiva, Recursos, Ação, Instrumentos, Critérios de análise e Eticidade.

O registro da data é importante ser apontada nos RE, pois trata-se de um período temporal, que pode indicar se o contexto do que fora realizado ainda se enquadra como atualidade e pertinente de ser incluso como discussão em outros trabalhos. A ausência desta informação pode não situar o leitor de quando ocorreu a ação relatada, bem como o contexto social. 
A duração corresponde ao tempo utilizado na vivência, podendo ser representada por carga horária, dias, meses, semestre e ano. Este item é necessário, pois indica um aspecto da experiência: se foi uma ação pontual, se integra um estudo longitudinal, por exemplo; esta informação é útil também para realizar a discussão de estudos, sobretudo os similares.

A descrição do local refere-se ao ambiente. Deste modo, as informações são concernentes a estrutura imóvel e móvel do local, bem como das áreas complementares usadas; para tanto, sugere-se o uso da observação qualitativa (MARCONI; LAKATOS, 2011). Neste elemento é apontada também a ventilação, tipo de piso, acessibilidade, segurança, fragilidades em decorrência das mudanças e/ou condições ambientais (exposição ao sol, chuva e vento), podendo citar ainda a existência de materiais extras. No entanto, é necessário cuidado para que não seja divulgado o nome da instituição ou empresa, bem como caracterizar de uma forma que fique ocultado a sua localização.

Destacar o eixo da experiência é algo fundamental, pois, pode ser entendido como resposta de um problema, de uma questão norteadora ou do que se trata a experiência; ou seja, é o principal assunto a ser contextualizado. Na pesquisa científica é importante a presença de uma pergunta, entendida também como objeto de estudo ou objeto da pesquisa, que ao ser formulada exige pensamento crítico do pesquisador (GRAZIOSI; LIEBANO; NAHAS, 2011).

A Caracterização da atividade relatada envolve vários aspectos: quantidade de pessoas (ação individual ou coletiva), presença profissional in lócus, grau de intervenção (acadêmica ou profissional), nível do ensino (médio, superior, técnico etc), áreas de conhecimento (específica, interdisciplinar, multidisciplinar, dentre outras). Tais informações possibilitam ao leitor uma compreensão aumentada das pessoas que participaram do estudo, uma vez que remetem ao campo acadêmico e profissional.

Em relação ao tipo da vivência, este elemento descreve o ambiente no qual o RE está situado, podendo ser do ensino (componente curricular - tipo o estágio), da pesquisa (projeto), da extensão (projeto), de programas institucionais (PIBIB), intercâmbio e residência. A especificação deste item evita entendimentos conflituosos e produções de conhecimentos equivocadas, como por exemplo, apenas citar que o ambiente do RE foi realizado na escola, esta indicação representa fragilidade, pois neste mesmo lugar pode ser cenário de estágio de esporte, estágio formal, intervenção com outro componente curricular, bem como ações de projetos e programas distintos. Portanto, é relevante especificar o ambiente, o que implica num entendimento correto do estudo, bem como na reprodução de suas informações coerentes.

No que se refere ao público, quem ler precisa saber com quem foi realizada a ação, sendo assim, pode-se optar por caracterizar de forma coletiva (escolares, mulheres, servidores 
púbicos, dentre outras), grupo especial (pessoas com diabetes, vírus da imunodeficiência humana, dentre outras especificidades) e misto (adultos e idosos). Tal item, além de ser informativo serve também como mecanismo de busca, uma vez que tal vocábulo pode representar palavra-chave, conforme Descritores em Ciências da Saúde ${ }^{3}$ ou termo na Pesquisa Tesauros ${ }^{4}$.

Os recursos são os itens que fazem parte da vivência, tendo a capacidade de potencializar as ações, que devem ser listados de acordo o pertencimento (instituição educacional, local da intervenção ou aquisição própria) e/ou conforme a fabricação (materiais comercializados, adaptados ou criados). Em decorrência dos mesmos recursos terem a possibilidade de serem também utilizados em outros estudos, tais informações são imprescindíveis.

Quanto à ação, é imprescindível a literatura para referenciar como foi feito o estudo, as etapas de planejamento, bem como o uso de protocolos e/ou fundamentar as intervenções a serem realizadas. Pois, sabe-se que um bom embasamento teórico pode identificar se já foi escrito muita coisa sobre o assunto relatado, qualificando a informação que está sendo registrada, por meio de um levantamento do que realmente seria relevante para o estudo. Além disso, sabe-se que outro propósito de uma revisão de literatura é estimular o raciocínio indutivo (ADAMS, 2007), e consequentemente, melhor explicar o que se pretende relatar.

Em relação às formas de coleta de dados/informações, há muitas opções com embasamento (instrumentos e estratégias) para o registro das informações, tais como: diário de bordo, observação qualitativa, grupo focal, roda de conversa dentre outros. A escolha da melhor forma de se obter as informações pode ser definida pelo levantamento feito na revisão de literatura, por meio da qual se definirá o método a ser aplicado na intervenção (ADAMS, 2007).

Os critérios de análise referem-se a forma como os dados obtidos serão avaliados. Importante destacar a relação deste item com o objetivo e seleção dos materiais e métodos. Desta forma, por exemplo, no RE vale destacar a importância de especificar descritivamente os procedimentos realizados nas análises, seja em uma vivência no ensino (SILVA; GOMES, 2018), por meio de avaliações, ou em pesquisas por meio dos dados estatísticos obtidos de determinada vivência (PEREIRA, 2013b).

No tocante a eticidade, é relevante destacar a necessidade dos cuidados éticos na execução da intervenção, bem como na escrita do texto acadêmico, quer seja com as instituições envolvidas, quer seja com as pessoas. Desta forma, é fundamental a proteção dos participantes

\footnotetext{
${ }^{3}$ https://decs.bvsalud.org/

${ }^{4}$ http://pergamum.inep.gov.br/pergamum/biblioteca/pesquisa_thesauro.php
} 
nas pesquisas científicas, sendo os Comitês de Ética em Pesquisa (CEP) um dispositivo para o controle social da ciência, tendo como referências as resoluções 466/2012 (ciências da saúde) e a 510/2016 (Ciências humanas e sociais) (SILVA, LIONÇO, 2018). Em suma, o RE referese à intervenção de quem vivenciou (autores) e quando houver a presença de forma especifica de participantes no texto, por meio de imagem e/ou fala, é relevante que a proposta seja avaliada previamente por um CEP.

Nos resultados, é importante relacionar com a questão norteadora e/ou objetivo do estudo, bem como escolher o formato que sintetiza e destaca os principais achados (CÁCERES; GÂNDARA; PUGLISI, 2011). Além disso, no RE ocorre as descrições das vivências conforme as etapas de ocorrência dos acontecimentos.

Os resultados indicam quais foram os achados da experiência, quando apontados de acordo com as etapas de planejamento mostra coerência acadêmica e organização metodológica. É importante que seja, se for o caso, a inovação do conhecimento trazida desta experiência.

$\mathrm{Na}$ discussão é apontado os achados fundamentais do estudo, dialogando como o conhecimento gerado pelos resultados pode colaborar para o cenário da ciência (CÁCERES; GÂNDARA; PUGLISI, 2011). Cabe destacar que no RE ocorrerá o enfrentamento criticoreflexivo da experiência, especialmente centrada nas principais experiências geradoras de aprendizagem. Ainda neste tópico, é importante, sempre que possível, o estabelecimento de relações com outras experiências, e, por fim a indicação das limitações e fortalezas da experiência.

Esta seção é composta por cinco elementos: Diálogo entre o relato e a literatura contribuições de autores e autoras para a realização da discussão dos dados; Comentários acerca das informações do relato - mecanismo de adicionar informações que propiciem relações relevantes, Análise das informações do RE - reflexões críticas da vivência; Dificuldades aspectos que dificultaram o processo; e Potencialidades - aspectos que potencializaram a experiência.

Embora tenha sido colocado de forma separada, é comum os resultados e discussão estarem juntas em algumas produções, como a de Santos, Flores e Pereira (2021) e Francisco, Figueiredo e Duek (2020), uma vez que isto depende das normas dos periódicos.

A conclusão tem como característica ser um texto curto com a síntese das descobertas e relacionado com o objetivo (CRUZ, 2020). Podendo também apresentar aplicações teóricas e práticas advindas da reflexão a partir da vivência. Tal seção é composta por: Finalidade - 
relacionar o texto com o objetivo do RE e Proposições - sugestões de realizações de estudos para melhorar o campo de conhecimento da área.

Ao final do RE, devem constar as referências das citações que embasam o conhecimento científico, por tal razão deve estar no final do estudo a lista com os trabalhos usados, uma vez que é ético mencionar a obra e sua autoria, citadas no corpo do texto para fundamentar o RE.

Diante da característica principal do RE, esta produção do conhecimento tem aproximação com os estudos descritivos, visto que descreve fenômenos a partir de possíveis estabelecimentos de relações da ação (GIL, 2008).

Partindo deste pressuposto, os autores do presente artigo destacam a presença de 4 tipos de descrição no RE: descrição informativa, referenciada, dialogada e crítica, que implicam na relevância para o meio acadêmico e também profissional, ou seja, tem dupla importância na produção do conhecimento: para discentes - ao compreender fenômenos de possibilidades interventivas da área e amadurecer academicamente, e para os profissionais - ao ter acesso a propostas que podem contribuir na ação laboral.

No intuito de possibilitar uma compreensão ampliada acerca dos tipos, abaixo haverá a explicação de cada uma juntamente com a indicação de quais elementos fazem parte do mesmo. Cabe apontar que uma seção do artigo pode apresentar elementos com tipos diferentes de descrição.

A descrição informativa consiste em caracterizar o cenário do estudo por meio dos aspectos elencados, constituindo como oportunidade de conhecer o trabalho (OLIVA; RODRIGUES, 2020). Este tipo de descrição é contemplado na introdução (objetivo), Materiais e Métodos (Período temporal, Descrição do local, Eixo da experiência, Caracterização da atividade relatada, Tipo da vivência, Público da ação interventiva, Recursos e Eticidade), Resultado, Discussão (Dificuldades e Potencialidades) e Conclusão (Finalidade e Proposições)

A descrição referenciada trata-se da parte que necessita de fundamentação. A produção de conhecimento na ciência está condicionada ao embasamento em obras científicas, não tendo assim espaço para "achismos" (SOARES, 2011). Este tipo de descrição é contemplado na: Introdução (Campo teórico), Materiais e Métodos (Ação, Instrumentos e Critérios de análise).

A descrição dialogada concerne à discussão, que "abriga os comentários sobre o significado dos resultados, a comparação com outros achados de pesquisas e a posição do autor sobre o assunto" (PEREIRA, 2013b, p. 537). Este tipo de descrição é contemplado na Discussão (Diálogo entre o relato e a literatura, Comentário acerca das informações do relato).

A descrição crítica refere-se a uma análise reflexiva do trabalho. A autocrítica é necessária para o alcance da criticidade, sendo que quando há o pensamento crítico a respeito 
da prática presente ou do passado colabora na melhoria da próxima; deste modo a reflexão sobre a prática é imprescindível na intervenção e formação profissional (FREIRE, 2006). Enfim, objetiva refletir a ação, revelando a sua nuance e possibilidades que agreguem ao campo acadêmico profissional. Este tipo de descrição é contemplado na Discussão (Análise das informações do RE).

No que concerne as limitações existentes nos RE, como se trata de um tipo de produção construída de forma similar as pesquisas observacionais, pode-se considerar alguns aspectos, como por exemplo, considerar que: "os comportamentos devem ser cuidadosamente definidos e observáveis" (THURBER, 2007; p.256), para que não aconteça um reducionismo do que se está sendo observado, e comprometa a descrição do comportamento crítico (THURBER, 2007). O mesmo autor, aborda outros aspectos que podem limitar as pesquisas observacionais, tais como: a prática do observador; treinamento inadequado; observar muitas coisas simultaneamente; a própria presença do observador; e a não utilização de mais de um observador, o que pode ocasionar menos eficiência e objetividade.

\section{Considerações Finais}

É necessário que a construção do conhecimento, nas suas diversas metodologias e modalidades, tenha parâmetros que norteiem a edificação de textos. Isto possibilita que estudantes e profissionais possam colaborar de forma ampliada para o progresso da ciência.

O conhecimento científico, advindo dos RE, beneficia o meio acadêmico e a sociedade, por contribuir na melhoria de intervenções e possibilitar o usufruto de futuras propostas de trabalho, respectivamente. No entanto, faz-se necessário mais pressupostos teóricos para a construção destes estudos, sobretudo pelas poucas referências que tratam do modus operandi.

Assim, o roteiro para elaboração de estudos da modalidade RE como construção de conhecimento, baseado em descrições informativa, referenciada, dialogada e crítica, colabora na compreensão dos elementos importantes nos RE, o que pode implicar na melhoria da formação acadêmica, ações laborais e campo das ciências.

\section{REFERÊNCIAS}

ABREU, S. M. B. DE; NÓBREGA-THERRIEN, S. M. Aprendizagens didáticas pela alteridade: experiência autoformadora na supervisão no PIBID Educação Física do IFCE. Cenas Educacionais, Caetité, v. 4, p. e10655, 2021. Disponível em: 
https://revistas.uneb.br/index.php/cenaseducacionais/article/view/10655. Acesso em: 28 mar. 2021

ALMEIDA, C. B. de. Projeto de extensão universitária em taekwondo: um relato de experiência (2005-2015). 1. ed. Fortaleza: RDS, 2016.

ADAMS, F. P. Desenvolvimento do problema e utilização da literatura. In: THOMAS, J.R.; NELSON, J.K.; SILVERMAN, S.J. Métodos de pesquisa em atividade física. $5^{\mathrm{a}} \mathrm{ed}$. Porto Alegre: Artmed, 2007.

ANGELO, F. F. et al. Divulgação Científica. Analecta, v. 6, p. 1, 2020. Disponível em: https://seer.cesjf.br/index.php/ANL/article/view/2738/1818. Acesso em 01 de jul. 2021.

BRETON, H.; ALVES, C. A. A narração da experiência vivida face ao "problema difícil" da experiência: entre memória passiva e historicidade. Revista Práxis Educacional, Vitória da Conquista, v.17, n. 44, p. 1-14, jan./mar., 2021. Disponível em:

https://periodicos2.uesb.br/index.php/praxis/article/view/8013/5526. Acesso em: 01 jul. 2021.

BUENO, W. C. Comunicação cientifica e divulgação científica: aproximações e rupturas conceituais. Informação \& Informação, [S.1.], v. 15, n. 1esp, p. 1-12, dez. 2010. Disponível em: https://brapci.inf.br/index.php/res/download/44839. Acesso em: 05 de jun. 2021.

CÁCERES, A. M.; GÂNDARA, J. P.; PUGLISI, M. L. Redação científica e a qualidade dos artigos: em busca de maior impacto. Jornal da Sociedade Brasileira de Fonoaudiologia São Paulo, v. 23, n. 4, p. 401-406, 2011. Disponível em: https://doi.org/10.1590/S217964912011000400019. Acesso em: 28 mar. 2021.

CAPOZZOLO, A. A. et al. Experience, knowledge production and health education. Interface (Botucatu), v.17, n.45, p.357-70, abr./jun. 2013. Disponível em: https://www.scielo.br/j/icse/a/xcCQjhYkr8NZZLPXYrf9mpg/abstract/?lang=pt. Acesso em: 10 de jun. 2021.

CHAUÍ, M. Convite à Filosofia. São Paulo: Ática. 2014.

CIARALLO, G. Caminhos da produção do saber acadêmico-científico: características, planejamento e estruturação do trabalho acadêmico. Brasília: UniCEUB, 2019. Disponível em:

https://repositorio.uniceub.br/jspui/bitstream/prefix/13676/1/EBOOK\%20CAMINHOS\%20D A\%20PRODUCAO\%20DO\%20SABER\%20ACADEMICO-CIENTIFICO.pdf.

CÓRDULA, E. B. L.; NASCIMENTO, G. C. C. A produção do conhecimento na construção do saber sociocultural e científico. Revista Educação Pública, Rio de Janeiro, v. 18, p. 1-10, 2018. Disponível em: https://educacaopublica.cecierj.edu.br/artigos/18/12/a-produo-doconhecimento-na-construo-do-saber-sociocultural-e-cientfico. Acesso em: 28 mar. 2021.

CRUZ, Roberto Moraes et al. Redação científica de artigos: problemas comuns. Revista Psicologia Organização e Trabalho, Brasília, v. 20, n. 3, p. 1-2, 2020. Disponível em http://pepsic.bvsalud.org/scielo.php?script=sci_arttext\&pid=S198466572020000300001\&lng=pt\&nrm=iso. Acesso em: 28 mar. 2021. 
DALTRO, M. R; FARIA, A. A de. Relato de experiência: Uma narrativa científica na pósmodernidade. Estudos e pesquisas em psicologia, Rio de Janeiro, v. 19, n. 1, p. 223 237, 2019. Disponível em http://pepsic.bvsalud.org/pdf/epp/v19n1/v19n1a13.pdf. Acesso em: 28 mar. 2021.

DIAS, A. M. I.; THERRIEN, J.; FARIAS, I. M. S. de. As áreas da educação e de ensino na Capes: Identidade, tensões e diálogos. Revista Educação e Emancipação, São Luís, v. 10, n. 1, p. 34-57, 2017. Disponível em:

http://www.periodicoseletronicos.ufma.br/index.php/reducacaoemancipacao/article/view/697 4/4395. Acesso em: 28 mar. 2021.

FLORES, F. F. et al. A Educação Física do CAPS: experiências do estágio em Guanambi BA. Cenas Educacionais, Caetité, v. 2, n. 1, p. 169-185, 2019. Disponível em: https://www.revistas.uneb.br/index.php/cenaseducacionais/article/view/6308. Acesso em: 28 mar. 2021.

FRANCISCO, F. B.; FIGUEIREDO, J. de P.; DUEK, V. P. práticas corporais de aventura nas dimensões do conteúdo: experiência na educação física infantil. Práxis Educacional, Vitória da Conquista, v. 16, n. 37, p. 508-524, Edição Especial, 2020. Disponível em:

https://periodicos2.uesb.br/index.php/praxis/article/view/4755/4717. Acesso em: 28 mar. 2021

FREIRE, P. Pedagogia da Autonomia: Saberes necessários a prática educativa. Sabotagem, 2006. Arquivo PDF. Disponível em:

http://www.letras.ufmg.br/espanhol/pdf/pedagogia_da_autonomia_-_paulofreire.pdf. Acesso em: 13 out. 2019.

GEERTZ, Clifford. O saber local: novos ensaios em antropologia interpretativa. Petrópolis, RJ: Vozes, 2004.

GIL, Antônio Carlos. Métodos e técnicas de pesquisa social. 6. ed. São Paulo: Atlas, 2008.

GRAZIOSI, M. E. S; LIEBANO, R. E; NAHAS, F. X. Elaboração da pergunta norteadora de pesquisa. Módulo científico da especialização em Saúde da Família modalidade a

Distância - Universidade Federal de São Paulo (UNIFESP). São Paulo: UNIFESP, 2011.

Disponível em:

https://www.unasus.unifesp.br/biblioteca_virtual/esf/1/modulo_cientifico/Unidade_12.pdf.

Acesso em: 28 mar. 2021.

HENDGES, A. P. Estágio não formal: vivenciando experiências com a Educação

Especial. Revista Insignare Scientia - RIS, Chapecó, v. 2, n. 3, p. 21-30, 2019. Disponível em: https://periodicos.uffs.edu.br/index.php/RIS/article/view/11177. Acesso em: 12 abr. 2021.

KASTRUP, V. A cognição contemporânea e a aprendizagem inventiva. In: KASTRUP, V.; TEDESCO, S.; PASSOS, E. (Orgs.). Políticas da cognição Porto Alegre: Sulina, 2008. p. 93112.

LÜDKE, M.; CRUZ, G. B. DA. Contribuições ao debate sobre a pesquisa do professor da educação básica. Formação Docente - Revista Brasileira de Pesquisa sobre Formação de Professores, v. 2, n. 3, p. 86-107, 18 dez. 2010. Disponível em: 
https://revformacaodocente.com.br/index.php/rbpfp/article/view/20/18. Acesso em 01 de jul. 2021.

MACHADO, L. Relato de experiência do intercâmbio realizado pelo programa Bramex.

Revista ComCiência, Guanambi, v. 5, n. 7, p. 86-93, 2020. Disponível em: http://www.revistacomciencia.com/arquivos/67.pdf. Acesso em: 12 abr. 2021.

MARCONI, M. de A.; LAKATOS, E. M. Metodologia científica. 6. ed. São Paulo: Atlas, 2011.

MARCONI, M. de A.; LAKATOS, E. M. Metodologia do trabalho científico. 7. ed. São Paulo: Atlas, 2013.

MARION, J. C.; DIAS, R.; TRALDI, M. C. Monografia para os cursos de Administração, Contabilidade e Economia. São Paulo: Atlas, 2002.

MENEZES, E. Método e limites da razão em Kant: enfoques preliminares. Cenas Educacionais, v. 4, p. e11425, 29 maio 2021. Disponível em: https://revistas.uneb.br/index.php/cenaseducacionais/article/view/11425/7918. Acesso em: 16 de jun. 2021.

MUSSI, R. F. de F. et al. Inquérito de Saúde em População Quilombola Baiana: relato de uma experiência em pesquisa epidemiológica. Revista Saúde e Pesquisa, Maringá, v. 13, n. 3, p. 675-685, 2020. Disponível em:

https://periodicos.unicesumar.edu.br/index.php/saudpesq/article/view/7525. Acesso em: 28 mar. 2021.

OLIVA, A. C. S. de; RODRIGUES, V. D. S. Estágio curricular supervisionado: percepções sobre a etapa de caracterização da escola. Revista Ciranda, Montes Claros, v. 4, n. 2, p. 5869, 2020. Disponível em:

https://www.periodicos.unimontes.br/index.php/ciranda/article/view/3242/3233. Acesso em: 28 mar. 2021.

OLIVEIRA JUNIOR, O. N. A técnica da escrita científica. Revista Brasileira de Ensino de Física, São Paulo, v. 37, n. 2, p. 2201--2202, 2015. Disponível em:

https://www.scielo.br/pdf/rbef/v37n2/0102-4744-rbef-37-02-2201.pdf. Acesso em: 28 mar. 2021.

OSSEGE, C. L. et al. Atuação do profissional de saúde residente no enfrentamento da covid19: um relato de experiência da Secretaria de Estado de Saúde do Distrito Federal. Cenas Educacionais, Caetité, v. 3, p. e8489. Disponível em: https://revistas.uneb.br/index.php/cenaseducacionais/article/view/8489. Acesso em: 28 mar. 2021.

PAIVA, P. W. S. C; MATOS, M. B. Relato de experiência como docente na Escola Estadual Indígena Riachuelo. Revista Práxis Educacional, Vitória da Conquista, v. 15, n. 31, p. 471492, 2019. Disponível em: https://doi.org/10.22481/praxis.v15i31.4683. Acesso em: 28 mar. 2021. 
PEREIRA, M. G. Preparo para a redação do artigo científico. Revista Epidemiologia e Serviços de Saúde, Brasília, v. 21, n. 3, p. 515-516, 2012a. Disponível em: http://scielo.iec.gov.br/pdf/ess/v21n3/v21n3a17.pdf. Acesso em: 28 mar. 2021.

PEREIRA, M. G. A introdução de um artigo científico. Epidemiologia e Serviços em Saúde, Brasília, v. 21, n. 4, p. 675-676, dez. 2012b. Disponível em http://scielo.iec.gov.br/scielo.php?script=sci_arttext\&pid=S167949742012000400017\&lng=pt\&nrm=iso. Acesso em: 28 mar. 2021.

PEREIRA, M. G. A seção de método de um artigo científico. Epidemiologia e Serviços em Saúde, Brasília, v. 22, n. 1, p. 183-184, 2013a. Disponível em http://scielo.iec.gov.br/scielo.php?script=sci_arttext\&pid=S167949742013000100020\&lng=pt\&nrm=iso. Acesso em: 28 mar. 2021.

PEREIRA, M. G. A seção de discussão de um artigo científico. Revista Epidemiologia e Serviços de Saúde, Brasília, v. 22, n. 3, p. 537-538, 2013b. Disponível em http://scielo.iec.gov.br/pdf/ess/v22n3/v22n3a20.pdf. Acesso em: 28 mar. 2021.

PEREIRA, M. G. Redação de artigo científico. Editorial. CBM. Cadernos brasileiros de medicina (IMPRESSO), v. 1, p. 6-6, 2018.

SANTOS, M. R. DOS; FLORES, F. F.; PEREIRA, T. D. Relato de experiência sobre aspectos do ensino da natação na primeira infância. Cenas Educacionais, Caetité, v. 4, p. e10885, 2021. Disponível em:

https://revistas.uneb.br/index.php/cenaseducacionais/article/view/10885. Acesso em: 28 mar. 2021.

SILVA, AL; GOMES, AM. Avaliação educacional: concepções e embates teóricos. Estudos em Avaliação Educacional, São Paulo, v. 29, n. 71, p. 350-384, maio/ago. 2018. Disponível em: http://publicacoes.fcc.org.br/index.php/eae/article/view/5048/3636. Acesso em

SILVA, E. Q.; LIONÇO, T. Cuidados éticos na pesquisa social: entre norma e reflexões críticas. Amazônica - Revista de Antrologia, Belém, v. 10, n. 2, p. 588-609, 2018. Disponível em: https://periodicos.ufpa.br/index.php/amazonica/article/view/6519. Acesso em: 28 mar. 2021.

SOARES, M. do C. S. Reflexões e orientações sobre a produção de textos científicos. Revista Univap, São José dos Campos, v. 17, n. 30, p. 81-99, 2011. Disponível em: https://edisciplinas.usp.br/pluginfile.php/279273/mod_resource/content/1/REDACAO_TEXT OCIENTIFICO.pdf. Acesso em: 28 mar. 2021.

SOARES, S. V.; PICOLLI, I. R. A.; CASAGRANDE, J. L. Pesquisa Bibliográfica, Pesquisa Bibliométrica, Artigo de Revisão e Ensaio Teórico em Administração e Contabilidade. Administração: Ensino e Pesquisa, v.19, n.2, p.1-19,2018. Disponível em: https://raep.emnuvens.com.br/raep/article/view/970/pdf_1. Acesso em: 01 de jun. 2021.

SOUSA, D. A. de; BARROSO, M. L. A formação inicial docente em Educação Física a partir do Programa Residência Pedagógica: um relato de experiência. Práticas Educativas, Memórias e Oralidades - Rev. Pemo, Fortaleza, v. 1, n. 2, p. 1-15, 2019. Disponível em: https://revistas.uece.br/index.php/revpemo/article/view/3570. Acesso em: 28 mar. 2021. 
STOCKMANNS, J. I. et al. Escrita/reescrita acadêmico-científica no ensino superior: um processo em construção permanente. Revista Mundi Sociais e Humanidades, Curitiba, v. 3, n. 3, p. 40-57, 2018. Disponível em:

http://periodicos.ifpr.edu.br/index.php?journal=MundiSH\&page=article\&op=view\&path\%5B $\% 5 \mathrm{D}=657$. Acesso em: 28 mar. 2021.

THURBER, J. Outros métodos de pesquisa descritiva. In: THOMAS, J.R.; NELSON, J.K.;

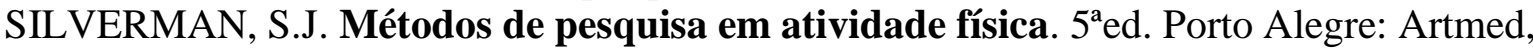
2007.

VIAN JR., O.; MENDES, W. V. O sistema de conjunção em textos acadêmicos: os mecanismos de sequenciamento e de explicação. Letras, v. 50, p. 163-186, 2015. Disponível em: https://periodicos.ufsm.br/letras/article/view/20209. Acesso em: 01 jun. 2021.

\section{SOBRE OS AUTORES:}

\section{Ricardo Franklin de Freitas Mussi}

Doutor em Educação Física pela Universidade Federal de Santa Catariana; Docente no Programa de Pós-Graduação em Ensino, Linguagem e Sociedade da Universidade do Estado da Bahia; Líder do Núcleo Internacional de Estudos em Direitos Humanos, Educação, Cultura e Saúde. Correio eletrônico: rimussi @ yahoo.com.br

(iD) https://orcid.org/0000-0003-1515-9121

\section{Fábio Fernandes Flores}

Mestrando em Ensino, Linguagem e Sociedade da Universidade do Estado da Bahia; Participante do Núcleo Internacional de Estudos em Direitos Humanos, Educação, Cultura e Saúde. Correio eletrônico: fabioedfgbi@gmail.com

iD https://orcid.org/0000-0002-1595-5868

\section{Claudio Bispo de Almeida}

Doutor em Ciências da Saúde pela Universidade Estadual do Sudoeste da Bahia; Docente no Programa de Pós-Graduação em Ensino, Linguagem e Sociedade da Universidade do Estado da Bahia; Participante do Núcleo Internacional de Estudos em Direitos Humanos, Educação, Cultura e Saúde. Correio eletrônico: cbalmeida@uneb.br

iD https://orcid.org/0000-0001-9486-7163 